\title{
Comments on: Study of the dynamical properties of water in disaccharide solutions
}

\author{
S. Magazù $\cdot$ F. Migliardo $\cdot$ M. T. F. Telling
}

(C) European Biophysical Societies’ Association 2016

This notice clarifies the relationship between Study of the dynamical properties of water in disaccharide solutions, authored by S Magazù, F Migliardo, MTF Telling, Eur Biophys J. 2007. DOI 10.1007/s00249-006-0108-0, and the following articles:

1. Transport and diffusion processes in trehalose-water solutions: theory and experiments, authored by $\mathrm{S}$ Magazù, G Maisano, F Migliardo, NP Malomuzh, EV Orlov, Chem Phys. 2006. DOI 10.1016/j.chemphys.2006.07.044.

2. $\alpha, \alpha$-Trehalose-water solutions. VIII. Study of the diffusive dynamics of water by high-resolution quasi elastic neutron scattering, authored by S Magazù, F Migliardo, MTF Telling. J Phys Chem. 2006. DOI 10.1021/ jp0536450.

3. Concentration dependence of vibrational properties of bioprotectant/water mixtures by inelastic neutron scattering, authored by S Magazù, F Migliardo, AJ Ramirez-Cuesta, J R Soc Interface. 2007. DOI 10.1098/ rsif.2006.0162.
4. Structural and dynamical properties of water in sugar mixture, authored by S Magazù, F Migliardo, MTF Telling, Food Chem. 2007. DOI 10.1016/j.foodchem.2007.05.097.

The articles were examined following the Committee on Publication Ethics (COPE) guidelines with regard to suspected redundant publication. The editors of the European Biophysics Journal recognize the partial re-use of text taken from older publications of the same authors or publications that were submitted in parallel to the one in question. Moreover, Figs. 2, 3, and 4a, b of the article have been partially re-used from article (2) listed above (DOI 10.1021/jp0536450).

However, it is felt that the re-use is not central to the validity of the conclusions and interpretations drawn from the data.

It was decided to publish this notice to alert readers to this conclusion. 